\section{MICROBIAL SEMI-SYNTHESIS OF AMINOGLYCOSIDIC ANTIBIOTICS BY MUTANTS OF S. RIBOSIDIFICUS AND $S$. KANAMYCETICUS}

Sir :

RINEHART Jr. et al. ${ }^{1)}$ reported biosynthesis of aminoglycosidic antibiotics by a mutant of Streptomyces fradiae. This mutant produced four new neomycin analogs, hybrimycin $\mathrm{A}_{1}, \mathbf{A}_{2}$, $B_{1}$ and $B_{2}$ in media containing streptamine and epi-streptamine.

During studies on the biosynthesis of aminoglycosidic antibiotics, we have also isolated deoxystreptamine-negative mutants of Streptomyces ribosidificus ${ }^{2)}$ and Streptomyces kanamyceticus $^{3}$.

The deoxystreptamine-negative strain of $S$. ribosidificus (named AF-1 strain) produced new ribostamycin ${ }^{4)}$ (SF-733) analogs by the addition of deoxystreptamine analogs or a neamine analog to the culture medium. Deoxystreptamine analogs examined were 1-N-methyl deoxystreptamine* (1), streptamine (2), myo-inosadiamine-1, 3** (2-epi-streptamine) $)^{5}$ (3), streptidine, $\mathrm{N}$-monoacetyl deoxystreptamine ${ }^{(\boldsymbol{)}}, \mathrm{N}, \mathrm{N}^{\prime}$-diacetyl deoxystreptamine and $\mathrm{N}, \mathrm{N}^{\prime}$-dimethyl deoxystreptamine*. Among them, 1, 2 and 3 were utilized by $\mathrm{AF}-1$ strain to produce new bioactive ribostamycins, 4, 5 and 6 , but no evidence was obtained on the incorporation of the other aminocyclitols to ribostamycins. Addition of neamine (7) and $3^{\prime}, 4^{\prime}$-dideoxyneamine ${ }^{7)}(8)$ in the cultured broth resulted in the biosynthesis of ribostamycin (9) and $3^{\prime}, 4^{\prime}$-dideoxy ribostamycin ${ }^{8)}(\mathbf{1 0})$, respectively. These ribostamycin analogs were isolated from each culture broth by column chromatography of Amberlite IRC$50\left(\mathrm{Na}^{+}\right.$type) and Amberlite $\mathrm{CG}-50\left(\mathrm{NH}_{4}{ }^{+}\right.$type $)$ resins developed with dilute ammonia.

1-N-Methyl ribostamycin (4) showed m.p. $239^{\circ} \mathrm{C}$ (dec.) $[\alpha]_{\mathrm{D}}^{28}+34.6\left(c 1.0, \mathrm{H}_{2} \mathrm{O}\right), R_{R m}=1.1$ (relative $\mathrm{R} f$ value against ribostamycin) on silicagel TLC developed with chloroform-butanolethanol-17\% ammonia $(2: 4: 5: 5)$. It had onefourth the bioactivity (against Bacillus subtilis) of ribostamycin. The NMR spectrum of 4 in $\mathrm{D}_{2} \mathrm{O}$ exhibited $\mathrm{N}$-methyl signal at $\delta 2.6$. The mass spectrum of $\mathrm{N}$-acetyl-O-trimethysilyl-4 showed $\mathrm{M}^{+}$at $m / e 1,063$, and the peaks indicating aminocyclotol moiety were shifted 14 mass units higher than those of ribostamycin.

4-O-(2, 6-Diamino-2, 6-dideoxy- $\alpha$-D-glucopyranosy1) 5-O-( $\beta$-D-ribofuranosyl) streptamine (2hydroxy ribostamycin) (5) showed m. p. $244^{\circ} \mathrm{C}$ (dec.), $[\alpha]_{\mathrm{D}}^{27}+36.1 \quad\left(c \quad 0.72, \mathrm{H}_{2} \mathrm{O}\right), \quad R_{R m}=0.92$ (TLC), and had one tenth the bioactivity of ribostamycin. The mass spectrum of $\mathrm{N}$-acetylO-trimethylsilyl-5 showed $\mathrm{M}^{+}$at $m / e 1,142$ and
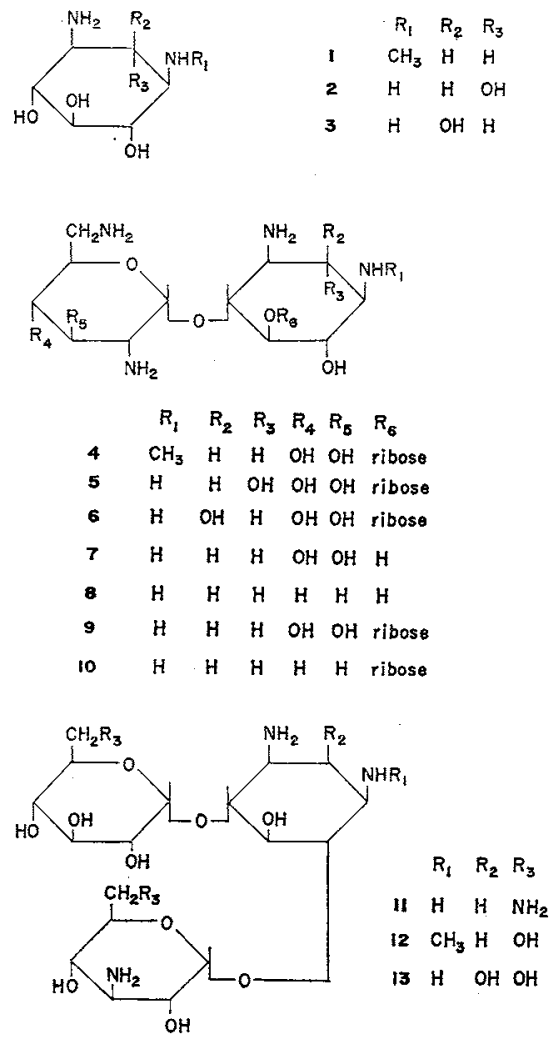

* These compounds were kindly supplied by Dr. S. Kondo, Institute of Microbial Chemistry.

** myo-Inosadiamine-1, 3 was kindly supplied by Prof. T. SUAm, Keio University. 
the peaks indicating aminocyclitol moiety were shifted 88 mass units higher than those of ribostamycin. This increment corresponded to an extra O-trimethylsilyl group in $\mathbf{5}$.

4-O-(2,6-Diamino-2, 6-dideoxy- $\alpha$-D-glucopyranosyl) 5-O-( $\beta$-D-ribofuranosyl) epi-streptamine(2epi-hydroxy ribostamycin) (6) showed m.p. $235^{\circ} \mathrm{C}$ (dec.), $[\alpha]_{\mathrm{D}}^{27}+37\left(\mathrm{c} 1.0, \mathrm{H}_{2} \mathrm{O}\right), R_{R m}=0.88$ (TLC). It had less than one tenth the bioactivity compared with ribostamycin. The mass spectrum of $\mathrm{N}$-acetyl-O-trimethylsilyl-6 was the same as that of 5 .

$3^{\prime}, 4^{\prime}$-Dideoxy ribostamycin (10) showed m.p. $234 \sim 236^{\circ} \mathrm{C}$ (dec.), $[\alpha]_{\mathrm{D}}^{24}+53$ (c $1.0, \mathrm{H}_{2} \mathrm{O}$ ). Compound 10 showed stronger activity than ribostamycin against Pseudomonas aeruginosa and kanamycin-ribostamycin resistant Escherichia coli, in accord with the results already reported $^{8)}$. The mass spectrum of N-acetyl-Otrimethylsilyl-10 showed $\mathrm{M}^{+}$at $m / e$ 878, and a strong peak at $m / e 213$ due to $\mathrm{N}$-acetyl-2', $3^{\prime}$, $4^{\prime}, 6^{\prime}$-tetradeoxy-2', 6'-diaminoglucose moiety.

In case of the deoxystreptamine-negative mutant of $S$. kanamyceticus which produced kanamycin (11), two new kanamycin analogs were obtained by the addition of two deoxystreptamine analogs, 1-N-methyl deoxystreptamine (1) and myo-inosadiamine-1, 3 (3). Isolation and purification procedure of these new kanamycin analogs were the same as described above for ribostamycin. However, when the structure of these antibiotics were examined by NMR and acid hydrolysis, it was found that these compounds were not the expected products, i.e. 1-N-methyl kanamycin and 2-epi-hydroxy kanamycin, but 4-O-( $\alpha$-D-glucopyranosyl) 6-O-(3amino-3-deoxy- $\alpha$-D-glucopyranosyl) $1-\mathrm{N}$-methyl2-deoxystreptamine (6'-deamino-6'-hydroxy-1$\mathrm{N}$-methyl kanamycin) (12) and 4-O-( $\alpha$-D-glucopyranosyl) 6-O-(3-amino-3-deoxy- $\alpha$-D-glucopyranosyl) 2-epi-streptamine (13). Addition of the other deoxystreptamine analogs such as streptamine, $\mathrm{N}, \mathrm{N}^{\prime}$-diacetyl deoxystreptamine and $\mathrm{N}$,
$\mathrm{N}^{\prime}$-dimethyl deoxystreptamine gave no bioactive substance.

Compound 12 showed m.p. $250^{\circ} \mathrm{C}$ (dec.) $[\alpha]_{D}^{27}$ $+81.5\left(c 1.0, \mathrm{H}_{2} \mathrm{O}\right)$. Acid hydrolysate $(6 \mathrm{~N} \mathrm{HCl}$, $100^{\circ} \mathrm{C} 45 \mathrm{~min}$.) of 12 gave three spots on PPC corresponding to 3-aminoglucose, N-methyl deoxystreptamine and glucose, developed with butanol-pyridine-acetic acid-water $(6: 4: 1: 3)$. The NMR spectrum of 12 in $\mathrm{D}_{2} \mathrm{O}$ exhibited $\mathrm{N}$ methyl signal at $\delta 2.6$.

Compound 13 showed m.p. $248^{\circ} \mathrm{C}$ (dec.), $[\alpha]_{D}^{27}$ $+113\left(c 1.0, \mathrm{H}_{2} \mathrm{O}\right)$ and acid hydrolysate of $\mathbf{1 3}$ gave 3-aminoglucose, inosadiamine and glucose on PPC. Compounds 12 and 13 exhibited weak bioactivity.

Detailed procedure on fermentation, isolation, physico-chemical properties and structure determination will be published in another paper.

The authors express their sincere thanks to Prof. H. UMEZAWA, Tokyo University and Institute of Microbial Chemistry and Prof. S. Umezawa, Keio University, for valuable suggestions and encouragement during the course of this work. They also wish to extend their gratitude to Prof. T. SUAm, Keio University, for suggestions and suppling sample of myo-inosadiamine-1, 3 .

\section{Mrchio Kojima \\ Research Laboratories of Meiji Seika Kaisha, Ltd. Morooka-cho, Kohoku-ku, Yokohama, Japan \\ AtsuYuki Satoh \\ Pharmaceutical Product Development Labo- ratories of Meiji Seika Kaisha, Ltd. \\ Horikawa-cho, Saiwai-ku, Kawasaki, Japan}

(Received August 17, 1973)

\section{References}

1) Shier, W.T.; K.L. Rinehart Jr. \& D. Gottlieb: Preparation of four new antibiotics from a mutant of Streptomyces fradiae. Proc. Nat. Acad. Sci. 63: 198 204, 1969

2) Shomura, T.; N. Ezaki, T. Tsuruoka, T. Nrwa \& T. NIIDA: Studies on antibiotic SF-773, a new antibiotic. I. Taxonomy, isolation and characterization. J. Antibiotics 23: 155 161, 1970

3) Umezawa, H.; M. Ueda, K. Maeda, K. YaGishita, S. KONDO, Y. OKaMI, R. UTAHARA, 
Y. Osato. K. NitTa \& T. Takeuchi: Production and isolation of a new antibiotic, kanamycin. J. Antibiotics, Ser. A 10: 181 188, 1957

4) Akita, E.; T. Tsuruoka, N. Ezaki \& T. Nitda: Studies on antibiotic SF-733, a new antibiotic. II. Chemical structure of antibiotic SF-733. J. Antibiotics 23: 173 183, 1970

5) Suami, T.; S. Ogawa, S. Naito \& H. Sano: Aminocyclotols. XVIII. A synthesis of myoinosadiamine-1, 3 and its derivatives. J. Org. Chem. 33: 2831 2834, 1968

6) Omoto, S.; S. Inouye, M. Korima \& T. NiIDA:
I ${ }^{13} \mathrm{C}-\mathrm{NMR}$ studies on ribostamycin and its related compounds. J. Antibiotics, in press

7) Umezawa, S., T. Tsuchiya, T. Ikehara \& H. UMEZAWA: Synthesis of $3^{\prime}, 4^{\prime}$-dideoxyneamine active against kanamycin resistant $E$. coli and Pseudomonas aeruginosa. J. Antibiotics 24: 711 $\sim 712,1971$

8) Umezawa, S.; T. Tsuchiya, D. IKeda \& H. UMEZAWA: Synthesis of $3^{\prime}, 4^{\prime}$-dideoxyribostamycin and $3^{\prime}, 4^{\prime}, 5^{\prime}$-trideoxyribostamycin active against kanamycin-resistant $E$. coli and $P$. aeruginosa. J. Antibiotics 25: 613 616, 1972 